\title{
Finite Element Analysis of Pallet-Nail Materials Used in Pallet Joint Design for Material Handling Works
}

\author{
Ö. KaraÇAli* AND A. TANER Ulguel
}

Department of Mechanical Engineering, Faculty of Engineering, Istanbul University, Avc1lar, Istanbul, 34320, Turkey

The aim of this research was to construct a nailing model based on the shape and material of the prepared nail-pallet joint. The finite element analysis was used due to the stress occurring in joining process, geometry of the nail and rigidness of the wood material. The behavior of palette system under loading was investigated according to material behavior and strain-stress distribution in this research. In order to simulate phenomena in real system, a simplified model of nail-pallet joint system was worked out. The simplifications concerned mostly geometry of nail. The nail was represented by height $h=60 \mathrm{~mm}$, corresponding with thickness of pallet. The effect of numerical analysis was determination of strains and stresses in working part of the nail-pallet. Results of analysis indicate diverse values of strains and stresses distribution in working part of the nail-pallet depending on its geometry. The numerical analysis of the operational nail-pallet joint system in simulated conditions of nailing in a pallet can be a basis for optimization of cutting edge geometry of joining tools as well as for selection of their mechanical properties and suitable materials. The results of this analysis are helpful for pallet design engineers for material selection and material handling interest.

DOI: $10.12693 /$ APhysPolA.125.183

PACS: 02.70.Dh, 62.20.F-

\section{Introduction}

Pallets are a vital component to storing and materials. The wood pallets are made of wood plates joined by metal nails and are used to stack manufactured products for shipping and storage [1]. Pallets vary in dimensions based on where they are being used and what they are being used for. The wooden pallet consists of two faces separated by structural members that provide clearance for the tines of fork-lift trucks or other mechanical handling equipment. Its use has developed dramatically for three main reasons: it protects the product, it improves storage and it makes distribution more efficient $[2,3]$. Design parameters specifically chosen for this research are detailed in Fig. 1. In the research reported here, yellow-poplar or aspen wood with medium density and 1 inch thickness is used to fabricate flat pallets. Most common type of nails used in pallet manufacturing is Q235 Steel with non-corrosive property [4] in this research.

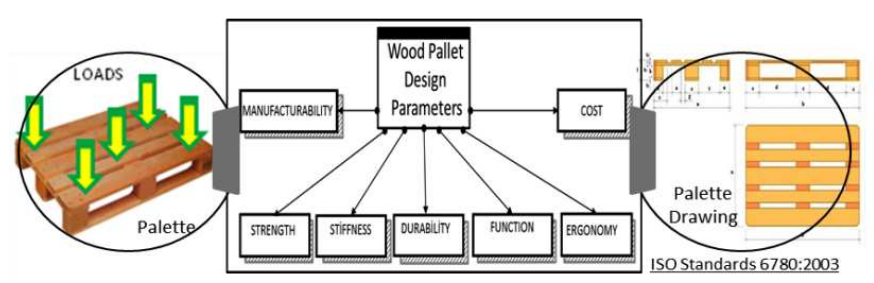

Fig. 1. Wood pallet design parameters and an example of palette.

*corresponding author; e-mail: ozdogank@istanbul.edu.tr
A pallet needs adequate stiffness and strength to function safely under conditions where it spans the rack support rails [5]. As shown in Fig. 1, design parameters of wood pallet that determine pallet suitability for a given application optimizing just one (i.e. manufacturability) will impact the others. This approach enables the joints to be compared with nailed and rigid joints in a pallet stiffness and strength theory [4].

\section{Pallet design: material and method}

In this research, wood pallet design activities were investigated as the main issue of the project as shown in Fig. 2. The core subject was to estimate the strength of the wooden pallet under preloaded forces and accordingly select the geometric shape and dimensions of the pallet. Material selection issues and metal connector type is determined for modeling of the pallet type in this research paper. A model of nailing process and calculation of total strength of the connection nail-pallet is presented.

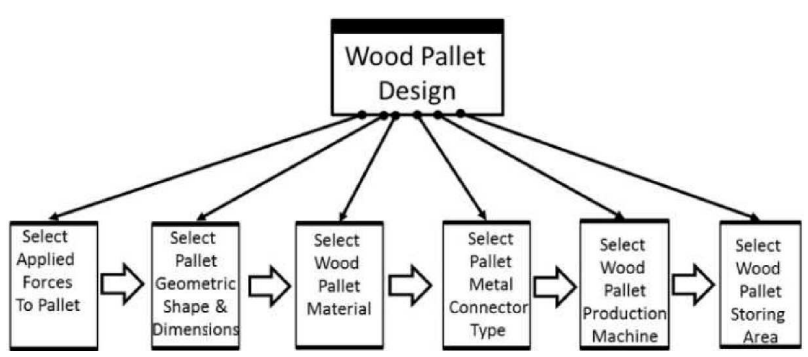

Fig. 2. Wood pallet design activities.

A model of the nail and pallet is depicted in Fig. 3. Explicit analysis of Euro Pallet type [2] is used in this 
research. Analysis was carried out by nailing into a corner of the pallet as shown in Fig. 3. Therefore, the pallet is correctly allocated into four equal wooden pieces and the nailing process of the pallet parts is discussed to explain technical details. The reason for this separation process is to exclude the elements that do not affect the processing areas. To obtain correct results, the number of elements and nodes are increased in this analysis.

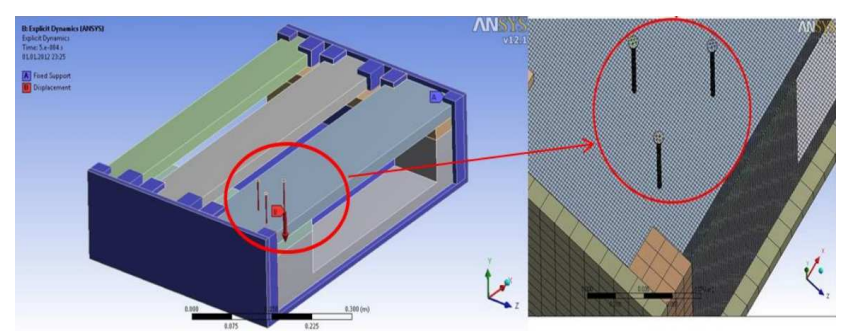

Fig. 3. Model of nailing wood pallet in ANSYS.

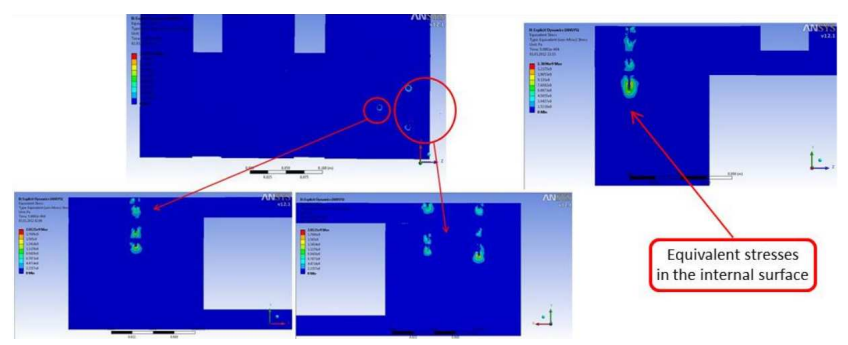

Fig. 4. Cross-section of pallet surface with equivalent stresses of the interior surfaces.
The finite elements mode [6]: mesh generation is one of the most critical aspects of engineering simulation in the pallet analysis. Too many cells may result in long solver runs, and too few may lead to inaccurate results. To optimize the solution, elements (mesh) separation process were carried out in ANSYS meshing module. Tetra (four-sided) triangle element is used for the separation process of the nail elements in explicit analysis. Nailing will happen on a flat surface pallet operation. The Hex (6-sided) rectangular elements are used in the process of fixing sections of the pallet. The following value is entered for separation process in the elements of the Explicit ANSYS module - element size: $0.0017 \mathrm{~mm}$.

As a result of the entered element values and the number of node points are obtained is as follows: number of elements 1290706, node: 1394290. Since the height of the nail is $60 \mathrm{~mm}$ long, it should be inserted into the pallet completely when $60 \mathrm{~mm}$ movement required. To do this across correctly all nail in "displacement" command is applied. Seated on the ground and secured the parts pallet in the pallet system as a built-in "fixed support" is determined.

Analysis settings: explicit analysis carried out has been determined for small time ranges as $0.0005 \mathrm{~s}$. As the time interval 0.005 second time is determined in step of 5420 realized.

The realized analysis results for aspen tree as the pallet materials: single nail correctly inserted into the pallet made from material of aspen is shown as the total deformation in Fig. 3. Very small size broken parts has been observed while the pallet nails hammered into the top surface of the pallet. As a result of this analysis that is also observed that ruptured broken small parts has emerged to a height of $0.4529 \mathrm{~m}$.
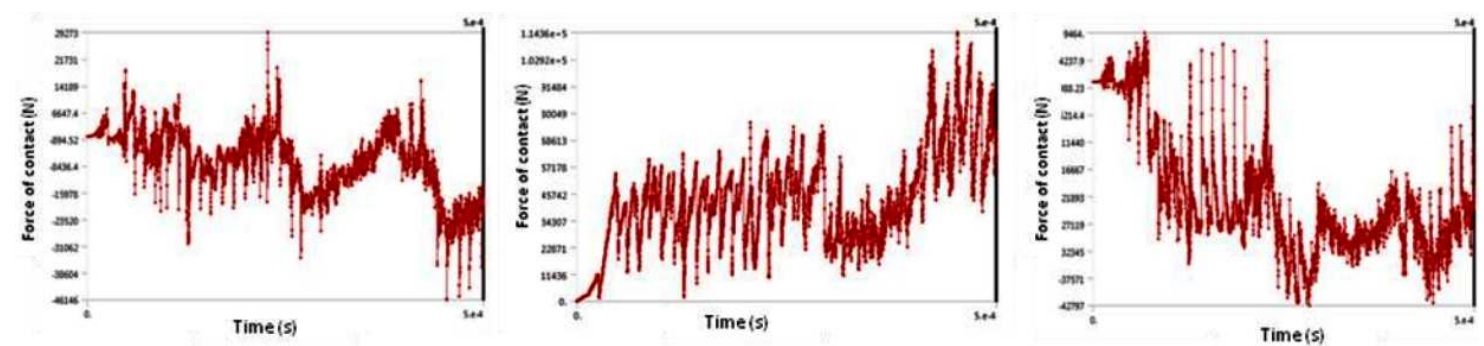

Fig. 5. Contact forces in Q235 steel nail. (left) Forces along the $X$-axis, (middle) forces along the $Y$-axis, (right) forces along the $Z$-axis.
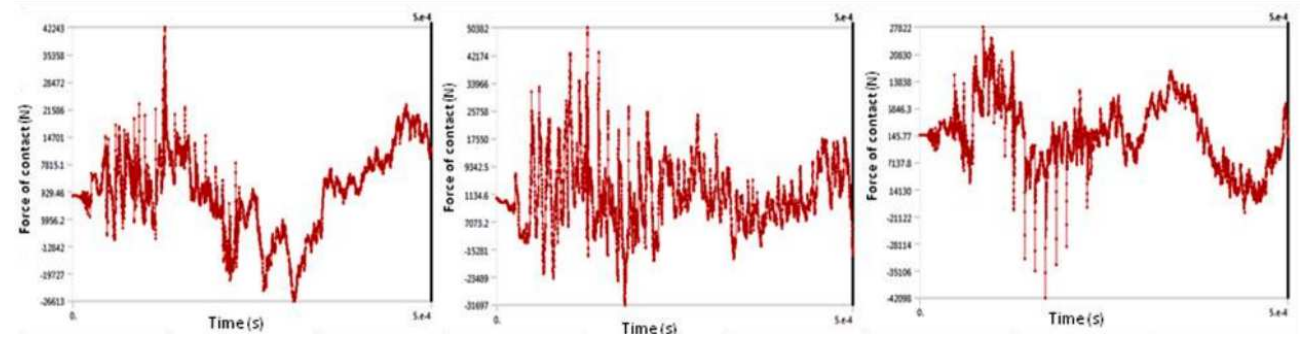

Fig. 6. Upper part contact force in pallet. (left) Forces along the $X$-axis, (middle) forces along the $Y$-axis, (right) forces along the $Z$-axis. 
A cross-section of pallet surface with equivalent stresses of the interior surfaces is shown in Fig. 4. Maximum equivalent stress occurred is $740.42 \mathrm{MPa}$ at the bottom of the pallet. Also a cross-section is taken to pass through the middle of the nails on the areas marked in the equivalent stress occuring in Fig. 4. There was no motion with other wooden parts observed in the aspen wood pallet system during nailing operation under compression process. Contact force occurring during nailing process in nail in structural modeling - ANSYS [6] is given in Fig. 5.

Manufactured from aspen wood on pallets formed during a single nail nailing forces: time-dependent changes in the force of contact are formed by the $X$-axis shown in Fig. 5. The minimum contact force is $-46146 \mathrm{~N}$ and the maximum contact force is found to be $29273 \mathrm{~N}$. Time-dependent changes in the force of contact are formed by the $Y$-axis graph during Q235-steel nail nailing in Fig. 6. Minimum contact force is $0 \mathrm{~N}$, the maximum contact force $1.1436 \times 10^{5} \mathrm{~N}$. Time-dependent changes in the force of contact are formed by the $Z$-axis shown in Fig. 6. Minimum contact force is $-42797 \mathrm{~N}$, the maximum contact force is $9464 \mathrm{~N}$.

Time-dependent changes in the force of contact are formed by the $X$-axis shown in Fig. 6 during the process of the upper part made of aspen wood nailing. The minimum contact force is $-26613 \mathrm{~N}$ and the maximum contact force is found to be $42243 \mathrm{~N}$. In the same upper part of the nailing operation, occurring minimum and maximum contact forces are $-31697 \mathrm{~N}$ and $50382 \mathrm{~N}$ in $Y$-axis in Fig. 6. Along the $Z$-axis time-dependent changes in the force of contact is given in Fig. 6. Minimum and maximum contact forces are found to be $-42098 \mathrm{~N}$ and $27822 \mathrm{~N}$.

\section{Conclusions}

The model presented in this study appears to be a useful tool for design purposes wood pallet. Different materials and geometries can be assessed to investigate different pallet constructions after determining the load and connector type. Experimental results demonstrate that the finite element modeling approach can be used to predict the deformation of engineered wood pallet subjected to non-homogeneous loads. This report summarizes the work to date, provides a general evaluation of the nailing process concept, and points out areas where further research activities could be focused.

\section{Acknowledgments}

This research was supported by Scientific Research Projects Coordination Unit of Istanbul University, project number: YADOP-10461.

\section{References}

[1] C. Lin, S. Hsiung, J. Appl. Sci. Eng. Technol. 1, 33 (2007).

[2] ISO Standards 6780:2003 - Flat pallets for intercontinental materials handling - Principal dimensions and tolerances.

[3] ISO 6780: Pallets for materials handling - Principal dimensions for flat pallets, 2001.

[4] T.J. Urbanik, J. Test. Eval. 13, 379 (1985).

[5] T.G. Weigel, Ph.D. Thesis, the Virginia Polytechnic Institute and State University, 2001.

[6] ANSYS Manual, ANSYS Inc., 2013, Release 11.0 Documentation for ANSYS Workbench/Analysis Settings [03 March 2013]. 